\title{
A comprehensive review on neurokinin-1 receptor antagonism in breast cancer
}

\author{
Mutukuru Mayuri ${ }^{1}$, Thangavel Mahalingam Vijayakumar ${ }^{2 *}$ \\ ${ }^{1}$ Department of Pharmacology, SRM College of Pharmacy, SRM Institute of Science and Technology, Kattankulathur, India. \\ ${ }^{2}$ Department of Pharmacy Practice, SRM College of Pharmacy, SRM Institute of Science and Technology, Kattankulathur, India.
}

\begin{tabular}{l}
\hline ARTICLE INFO \\
\hline Received on: $09 / 11 / 2020$ \\
Accepted on: $16 / 03 / 2021$ \\
Available online: $05 / 05 / 2021$
\end{tabular}

Key words:

Breast cancer, metastasis, neurokinin 1 receptor, pathogenesis, cell viability.

\begin{abstract}
Breast cancer is one of the most prevalent cancer types globally, and has caused more deaths in women. The undecapeptide substance $\mathrm{P}$ is participated in various physiological processes like emesis, pain, inflammation, antitumor activity, and also regulates the function of gastro intestinal tract and central nervous system by binding to NK1R. substance P (SP)/NK1R regulates the proliferation, migration, and metastasis of breast cancer cells and also controls the proliferation of endothelial cells for angiogenesis. It exerts an antiapoptotic influence as well. In breast cancer, NK1R is over expressed. It has been demonstrated that the NK1R antagonist inhibits the breast cancer cell proliferation in a concentration dependent manner, induces the cell death by apoptosis and inhibit angiogenesis. The antagonists of the NK1 receptor are safe and well tolerated. In this paper, we reviewed the extensive studies that have been done on the SP/NK1R system in breast cancer. In fact, only currently available are NK1R antagonist Aprepitant and its analogues. The research must, therefore, focus on drugs with elevated anti-tumor activity with lesser side effects. Modulating the function of the NK1 receptor as a therapeutic strategy is, therefore, the most attractive area of research for the design and creation of new molecules with important clinical values for the future.
\end{abstract}

\section{INTRODUCTION}

Cancer has been one of the most threatening human diseases for years. Approximately in 2020, 1,806,590 new cancer cases and 606,520 cancer deaths have been diagnosed in US (Siegel et al., 2020). 18.1 million cancer cases have been reported worldwide in 2018 and 9.6 million cancer cases would lead to expected deaths. As per the GLOBOCAN project of the International Cancer Agency in India, cancer growth is expected to double in the next 20 years, from more than a million new cases in 2012 to greater than 1.7 million cases by 2035 (Mallath et al., 2014).

Presently, breast cancer (BC) is the most predominant form of cancer among females, and several cancer studies have been reported (Toğaçar et al., 2020). In 2019, 268,600 new invasive breast cancers among women and 2,670 cases in men

\footnotetext{
"Corresponding Author

T. M. Vijayakumar, Department of Pharmacy Practice, SRM College of Pharmacy, SRM Institute of Science and Technology, Kattankulathur, India.E-mail:vijaypractice@yahoo.com
}

were diagnosed in the study (Miller et al., 2019). There are many types of cancer documented. Breast cancer therapy requires either substance or drug inhibiting the cancer growth by interacting with the functioning of some molecules responsible for cancer growth and cell survival (Mittendorf et al., 2016; Rugo, 2016).

Breast cancer cells may over express certain receptors, which triggers signalling pathways and further it regulates gene transcription for tumour proliferation, invasion, migration, and angiogenesis ( $\mathrm{Pal}$ et al., 2011). It controls gene transcription pathways for tumour proliferation, invasion, migration, angiogenesis, and more (Pal et al., 2011). There are different kinds of pathways or receptors that are active in breast cancer. In this way, the P/NK1 receptor system also plays a pivot role in the pathogenesis of breast tumour (Masoud and Pagès, 2017).

NK1 receptor activation acts as a mitogen which is involved in mitogenesis, angiogenesis, cell migration, and metastasis (Mehboob et al., 2015). NK1R inhibition suppresses cancer growth in many forms of cancer, creating an interesting target for cancer (Palma et al., 2006). Human tumour cells have NK1 receptors that are over-expressed than normal human cells (Munoz et al., 2010; 2011). 
Substance $P$ is an 11 amino acid neuropeptide consisting of a particular C-terminal sequence of phe-x-gly-leu-met-NH2, encoded by the gene tachykinin 1 . Substance $\mathrm{P}$ is amphiphilic in nature, where the $\mathrm{N}$-terminal has a positive charge and the $\mathrm{C}$-terminal has a negative charge (Lazarczyk et al., 2007; Muñoz and Coveñas, 2014).

Substance P has a good affinity with the NK1 receptor, a G protein coupled receptor (GPCR) and encoded by the TACR1 gene (Garcia-Recio et al., 2013). It has two isoforms with 407 residues, a maximum length and a low-affinity NK1R-T receptor with 311 amino acids, a truncated one, such as the high-affinity NK1R-F receptor. The NK1 receptor has three extracellular (EL1, EL2, and EL3) transmembrane domains and three intracellular coils $(\mathrm{C} 1, \mathrm{C} 2$, and $\mathrm{C} 3)$. The $\mathrm{C}$-terminal is extended into a cell's cytoplasm. The intracellular region is related to heterotrimeric $\mathrm{G}$ protein-coupled with $\alpha, \beta, \gamma$ subunits, and guanosine diphosphate (GDP) (Garcia-Recio and Gascón, 2015; Lazarczyk et al., 2007).

Substance P/NK1R system is involved in several physiological and pathological processes such as paracrine and endocrine secretions, dissemination of pain, vasodilation, and development of cells. Anxiety, stress, emesis, and depression are also associated with it. In multiple cancer cell lines, such as breast carcinoma, malignant gliomas, metastatic melanomas, ovarian and prostate cancer, various in vitro studies have shown that SP and NK1 receptors are increased (Garcia-Recio and Gascón, 2015; Mayordomo et al., 2012; Rosso et al., 2012).

Although, earlier research on function of substance $\mathrm{P} / \mathrm{NK} 1$ receptors in breast cancer provided finite data on the recruitment of substance P/NK1R in the potential therapeutic regimen as a target. The scientific papers on the association substance P/NK1R system in the progression of breast cancer were summarized in this study.

\section{Evidences association with substance P/NK1R and breast cancer}

No intensive study on the P/NK1R mechanism in breast cancer pathogenesis has been performed. Some recent studies, however, have reported:

I. The study conducted by Mehboob et al. (2020) stated that immunohistochemistry showed the expression of substance $\mathrm{P} / \mathrm{NK} 1 \mathrm{R}$, where $68 \%$ of breast cancer cases reported overexpression of SP. $82.6 \%$ of SP-positive cases were associated with $<60$ years of age, $52.17 \%$ of SP-positive cases were seen in premenopausal women, and $47.82 \%$ in postmenopausal women. In addition, $82.6 \%$ of the interaction between SP and estrogen receptor (ER) and $78.2 \%$ between SP and human epidermal growth factor receptor (HER) were recorded in the research. Overall, the studies suggest that patients with breast cancer express SP/NK1R and also display the relationship between SP, ER, and HER.

II. In another study by Dvoodian et al. (2019), 41 females with breast cancer and 34 healthy individuals were studied. Serum levels of Breast cancer patients $(16.11+3.320 \mathrm{ng} / \mathrm{ml})$ showed substantially high levels of SP than healthy persons $(5.05+1.087 \mathrm{ng} / \mathrm{ml})$. Moreover, based on the severity of staining, the percentage of NK1R was calculated where, $80 \%$ tumor biopsies among samples recorded higher percentage of stained cells than control (20\%). In addition, $90 \%$ of the tissue distribution was seen in tumor biopsies and $10 \%$ of the tissue distribution was seen in healthy groups. Furthermore, real time polymerase chain reaction (RT-PCR) study showed a rise of NK1R mRNA in BC. Overexpression of NK1R is seen as usual in the membrane, cytoplasm, and BC nucleus. Finally, the analysis examined SP levels and the important association between SP/NK1R, tumor size, and HER-2 in breast cancer patients than normal individuals.

III. SP induced cell migration in a dose-dependent manner compared to the control group, according to the Silvia Gutierrez report. The study further supported the association between nociceptive afferent neurons and tumor cells that also spread disease and pain. This effect was demonstrated by the release of kininogen by SP with pronociceptive and protumorigenic function. SP also enhances the expression of cognate receptors like NKR2, RAMP1 and CALCRL (Gutierrez and Boada, 2018).

IV. The Nizam and Erin (2018) research tested both NK1 and NK2 receptors in Balbe mice breast carcinoma cells. In non-metastatic $67 \mathrm{~N}$ cells, full-length NK1R showed lower expression than in metastatic cells. By inhibiting the activity of NK1R, they also investigated the anti-proliferative effects of RP67580 (NK1R antagonist). Admittedly, RP67580 at 30 $\mu \mathrm{m}$ conc inhibits cell proliferation in 4TBM and 4THM at $765.477 \%$ and $764.55 \%$, respectively. In addition, RP67580 decreases MIP-2 at the same concentration and also induces phosphorylation of the protein kinase B (AKT) without altering the extracellular-signal-regulated kinase (ERK). MIP2 , an angiogenic and inflammatory chemokine which causes cancer cell metastasis, is highly secreted by breast cancer cells.

V. The findings of the Garcia-Racio et al. (2015), study showed that the proinflammatory cytokine / substance $\mathrm{P}$ co-activation of HER-2 and epidermal growth factor receptor (EGFR) in $\mathrm{BC}$ is a c-Src and matrix metalloproteinases (MMP) based mechanism. They documented the SP induced phosphorylation c-Src Tyr41 with the aid of time course studies. In addition, NK1 antagonists have been documented in Sk-BR-3 and BT 474 cells to significantly block c-Src phosphorylation. In addition, in the Sk-BR-3 and BT 474 cell lines, the NK1 antagonist substantially inhibit the phosphorylation of c-Src. Non-significant inhibition was observed in the MDA-MB-453 and MDA-MB-468 cell lines. In addition, the triple inhibition of NK1R leads to down regulation of c-Src phosphorylation and is probably caused by tachykinin signaling in $\mathrm{BC}$ cells.

VI. The study by Munoz et al. (2014), documented the expression of mRNA for NK1R in MCF-7, MDA-MB-468, MT-3, MCF$10 \mathrm{~A}$, and 12A human cells with the assistance of Western blot analysis and PCR analysis. The NK1R expression was further shown by RT-PCR analysis using the $\beta$-actin as a control. The ratio was $1.6+3.9$ for the non-tumor cell line HEK-293 and $1.8+1.92$ for MCF-12A and $2.1+1.96$ for the cell lines of epithelial breast cancer MCF-10A. Therefore, in $\mathrm{BC}$ cells and normal cell lines, $20 \%-60 \%$ of NK1R mRNA levels were higher. In addition, the study performed on aprepitant, L-733,060, and L-732,138 antitumor activity and demonstrated maximum NK1R activity inhibition in 
dose dependence manner. NK1R and SP immunoreactivity in $\mathrm{BC}$ cells and apoptosis were also observed by the staining technique of DAPI.

\section{DISCUSSION}

In this study, the complements and results of previously published research findings on the role of the SP/NK1R system in $\mathrm{BC}$ cell metastasis were reported. The NK1 R expressed on the cytoplasm and plasma membrane in $\mathrm{BC}$ cells by immune receptor activity was documented in one of the studies (Esteban et al., 2009; Muñoz et al., 2010). The activated SP/NK1 R system activates the signaling cascade causing mitogen activated protein kinases (MAPKs) to lead to cell calcium mobilization and phosphoinositide hydrolysis (Kim et al., 2019) and the Akt pathway phosphorylates shown in the figure (Backman and Danielson, 2013). Furthermore, the activation of PI3K-, NF-kB pathways increase after binding of SP with NK1R (Fig. 1) (Mayordomo et al., 2012; Reddy et al., 2009).
In regards to nociception $\mathrm{BC}$ cells secretes SP. Increased level of SP modulates inflammatory cytokinin's like IL4, IL6, and IL10 by increasing the permeability of blood brain barrier(BBB) (Kim et al., 2019; Mehboob et al., 2020; Rodriguez et al., 2014). In addition, it contributes to cell division, cell progression, vasculogenesis, and metastasis by step-down apoptosis via antiapoptotic protein kinase (Muñoz et al., 2014). Earlier studies suggested that the SP induced BC cell adhesion and transmigration over the human brain microvascular endothelial cells (HBMECs) where, it is independent of the mediated pathway of MMP-9. SP induces proinflammatory cytokine activation and loss of quiescence and causes HBMECs to become destabilized via Tumor necrosis factor- $\alpha$ and Ang-2 secretions. Both of these molecules strengthen angiogenesis and migration of inflammation cells (Rodriguez et al., 2014; Scharpfenecker et al., 2005).

Activated GPCR is slightly regulated in certain cancer cell types by transmodulation of the endothelial growth factor receptor, like tyrosine kinase activity receptor EGFR, HER2,

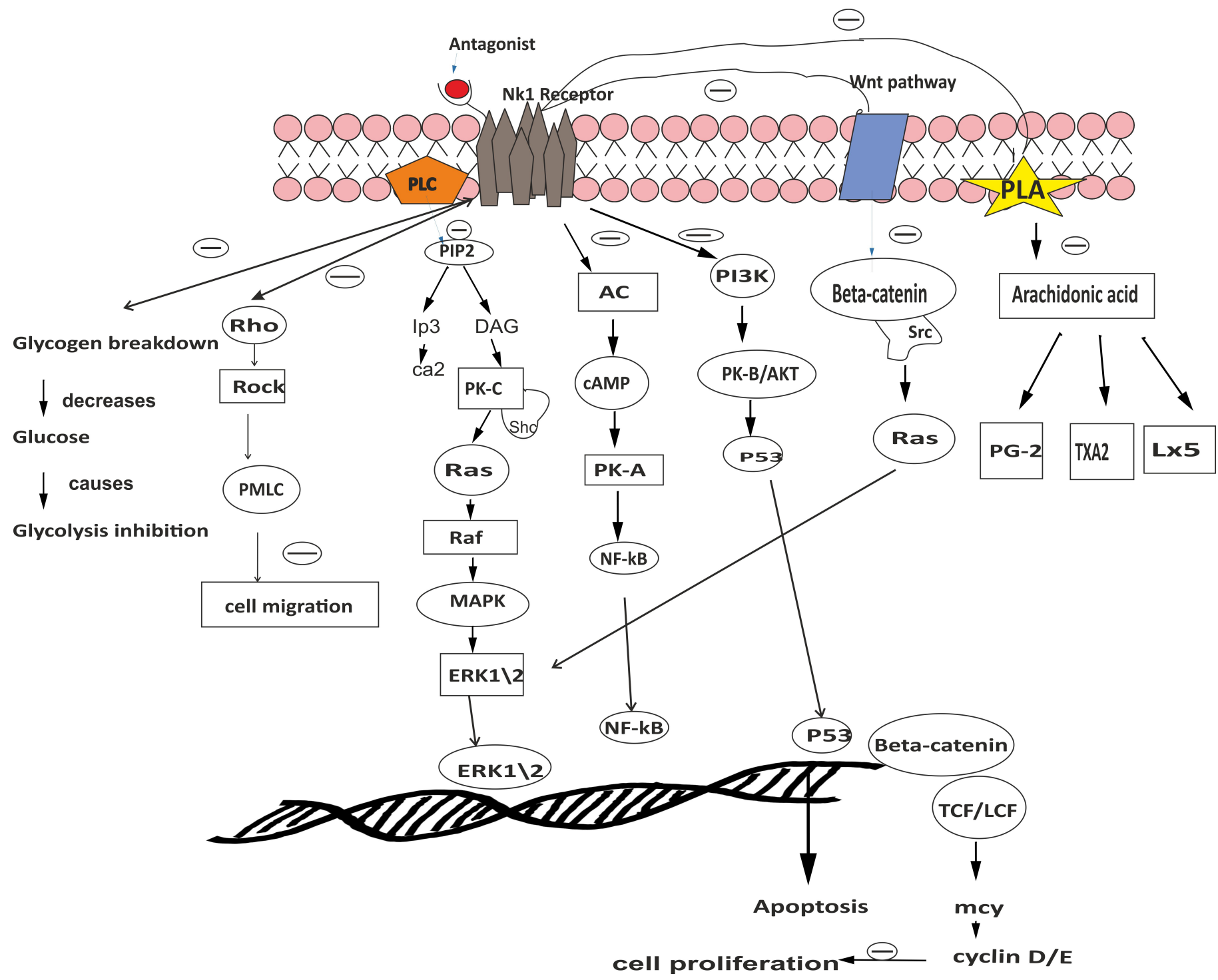

Figure 1. Explains a brief mechanism of NK1 R antagonist (Aprepitant) in breast cancer. 
HER3, and HER4 (Olayioye et al., 2000; Stern, 2000). These pathways indicate a crucial role in initiating the development of the tumor. HER-2 is especially over-expressed in BC, approx. $25 \%$ and linked to poor prognosis and high mortality rate. Garcia et al. (2013), stated the SP induced proinflammatory cells enhance cancer cell progression by activating the EGFR, HER2. In addition, an in vitro study stated that increased SP exposure enhances the expression of EGFR and HER2 in cell lines. NK1R antagonism is also synergistic with anti-EGFR and anti-HER2 therapies and has demonstrated a substantial decrease in cell survival. Dual inhibition of these receptors may be the new strategy in cancer treatment.

The persistent activation of HER2 by SP autocrine signaling, which develops tumor pathogenesis and drug resistance in BC, was determined in one study (Garcia-Recio et al., 2013). Patients may feel pain during cancer metastasis and this is due to excessive sensory nociception activation associated with peripheral sensors. This leads to excessive release of neuroinflammatory peptides like Substance P, calcitonin gene-related peptide,, and neurokinin A.

The SP raises MDA-MB-231LUC chemokines and further improves the acute release of Kininogen, Silvia Gutierrez, and Danilo said. In total, it demonstrates pronociceptive and protumorigenic roles and promotes metastasis of the bone marrow. This demonstrates the link between the sensory nociception neurons and the progression of cancer (Gutierrez and Boada, 2018; Huang and Korlipara, 2010).

The main function of SP/NK1R system in the cancer development has thus been suggested on the basis of recent scientific evidence (Munoz et al., 2011). It is extensively located in central and peripheral nervous system and displays a great affinity toward NK1R. It was clarified that inhibition and $\mathrm{BC}$ recurrence could be significantly involved in SP and NK1R (Muñoz et al., 2010) and moreover in tumor cell viability. The activation SP/ NK1R system induces mitogenesis and cancer proliferation, growth of blood capillaries, and neoangiogenesis (Bigioni et al., 2005; Huang et al., 2010; Mayordomo et al., 2012; Muñoz et al., 2014). NK1R antagonists inhibit both DNA synthesis and cell proliferation via the MAPK pathway.

Aprepitant (NK1R antagonist) is approved by the Food and Drug Administration and is widely used to treat nausea and vomiting caused by chemotherapy. Cell apoptosis is increased and the pathways of Akt/p53 are blocked (Bayati et al., 2016; Li et al., 2016; Mayordomo et al., 2012; Munoz et al., 2011; Quartara et al., 2009). NK1R antagonists such as aprepitant and L-732,138 completely attenuate the $\mathrm{BC}$ cell growth and induce apoptosis further. In addition, other forms of cancer such as pancreatic cancer, laryngeal cancer, retinoblastoma, neuroblastoma, glioma, melanoma, retinoblastoma, colon and gastric cancer have demonstrated anticancer activity (González Moles et al., 2008; Muñoz and Rosso, 2010; Muñoz et al., 2007, 2008, 2010).

In addition, the NK1R antagonist also prevents the development of the $\beta$-arrestin complex that allows ERK1/2 translocation into the cell nucleus; attenuates cell proliferation and induces the mortality rate of cancer cells. The NK1R antagonist reduces phosphorylation of $\mathrm{Akt}$, leading to poly polymerase (ADP-ribose) polymerase proteolysis and caspase-3 cleavage (Akazawa et al., 2009; DeFea et al., 2000). Munoz confirmed that, for 45 days, a patient suffering from chronic obstructive pulmonary disease and non-small cell lung carcinoma underwent radiotherapy along with Aprepitant. Patient showed positive signs without adverse effects and even with decreased tumor volume (Muñoz et al., 2019; Shaik-Dasthagirisaheb et al., 2013).

\section{CONCLUSION}

Recent findings strongly supporting the role of the SP/NK1R system in the pathogenesis of breast cancer and associated with poor prognosis were examined. The evidence indicates that NK1R antagonists provide a great opportunity for researchers to further synthesize and modulate NK1R-active compounds as a potential cancer management therapeutic agent. In addition, in order to provide full evidence of NK1R antagonist effects in breast cancer treatment, more clinical studies must be undertaken.

\section{ACKNOWLEDGMENTS}

The authors would like to thank Prof. K.S. Lakshmi, Dean, and SRM College of Pharmacy for her kind support and guidance.

\section{AUTHOR CONTRIBUTIONS}

All authors made substantial contributions to conception and design, acquisition of data, or analysis and interpretation of data; took part in drafting the article or revising it critically for important intellectual content; agreed to submit to the current journal; gave final approval of the version to be published; and agree to be accountable for all aspects of the work. All the authors are eligible to be an author as per the international committee of medical journal editors (ICMJE) requirements/guidelines.

\section{FUNDING}

There is no funding to report.

\section{CONFLICTS OF INTEREST}

The authors report no financial or any other conflicts of interest in this work.

\section{ETHICAL APPROVALS}

Not applicable.

\section{PUBLISHER'S NOTE}

This journal remains neutral with regard to jurisdictional claims in published institutional affiliation.

\section{REFERENCES}

Akazawa T, Kwatra SG, Goldsmith LE, Richardson MD, Cox EA, Sampson JH, Kwatra MM. A constitutively active form of neurokinin 1 receptor and neurokinin 1 receptor-mediated apoptosis in glioblastomas. J Neurochem, 2009; 109(4):1079-86.

Backman LJ, Danielson P. Akt-mediated anti-apoptotic effects of substance $\mathrm{P}$ in anti-fas-induced apoptosis of human tenocytes. J Cell Mol Med, 2013; 17(6):723-33.

Bayati S, Bashash D, Ahmadian S, Safaroghli-Azar A, Alimoghaddam K, Ghavamzadeh A, Ghaffari SH. Inhibition of tachykinin $\mathrm{NK}$ (1) receptor using aprepitant induces apoptotic cell death and G1 arrest through Akt/p53 axis in pre-B acute lymphoblastic leukemia cells. Eur J Pharmacol, 2016; 791:274-83.

Bigioni M, Benzo A, Irrissuto C, Maggi CA, Goso C. Role of NK-1 and NK-2 tachykinin receptor antagonism on the growth of human 
breast carcinoma cell line MDA-MB-231. Anticancer Drugs, 2005; 16(10):1083-9. doi:10.1097/00001813-200511000-00007

Davoodian M, Boroumand N, Mehrabi Bahar M, Jafarian AH, Asadi M, Hashemy SI. Evaluation of serum level of substance P and tissue distribution of NK-1 receptor in breast cancer. Mol Biol Rep, 2019; 46(1):1285-93; doi:10.1007/s11033-019-04599-9

DeFea KA, Vaughn ZD, O'Bryan EM, Nishijima D, Déry O, Bunnett NW. The proliferative and antiapoptotic effects of substance $P$ are facilitated by formation of a $\beta$-arrestin-dependent scaffolding complex. Proc Natl Acad Sci, 2000; 97(20):11086-91; doi:10.1073/pnas.190276697

Esteban F, Gonzalez-Moles MA, Castro D, Martin-Jaen Mdel M, Redondo M, Ruiz-Avila I, Muñoz M. Expression of substance P and neurokinin-1-receptor in laryngeal cancer: linking chronic inflammation to cancer promotion and progression. Histopathology, 2009; 54(2):258-60; doi:10.1111/j.1365-2559.2008.03193.x

Garcia-Recio S, Gascón P. Biological and pharmacological aspects of the NK1-receptor. Biomed Res Int, 2015; 2015:495704; doi: $10.1155 / 2015 / 495704$

Garcia-Recio S, Fuster G, Fernandez-Nogueira P, Pastor-Arroyo EM, Park SY, Mayordomo C, Ametller E, Mancino M, Gonzalez-Farre X, Russnes HG, Engel P, Costamagna D, Fernandez PL, Gascón P, Almendro V. Substance $P$ autocrine signaling contributes to persistent HER2 activation that drives malignant progression and drug resistance in breast cancer. Cancer Res, 2013; 73(21):6424-34.

Garcia-Recio S, Pastor-Arroyo EM, Marín-Aguilera M, Almendro V, Gascón P. The transmodulation of HER2 and EGFR by substance $\mathrm{P}$ in breast cancer cells requires $\mathrm{c}-\mathrm{Src}$ and metalloproteinase activation. PloS One, 2015; 10(6):e0129661; doi:10.1371/journal. pone. 0129661

González Moles MA, Mosqueda-Taylor A, Esteban F, GilMontoya JA, Díaz-Franco MA, Delgado M, Muñoz M. Cell proliferation associated with actions of the substance $\mathrm{P} / \mathrm{NK}-1$ receptor complex in keratocystic odontogenic tumours. Oral Oncol, 2008; 44(12):1127-33.

Gutierrez S, Boada MD. Neuropeptide-induced modulation of carcinogenesis in a metastatic breast cancer cell line (MDA-MB-231(LUC+)). Cancer Cell Int, 2018; 18:216; doi:10.1186/s12935-018-0707-8

Huang SC, Korlipara VL. Neurokinin-1 receptor antagonists: a comprehensive patent survey. Expert Opin Ther Pat, 2010; 20(8):1019-45.

Huang WQ, Wang JG, Chen L, Wei HJ, Chen H. SR140333 counteracts NK-1 mediated cell proliferation in human breast cancer cell line T47D. J Exp Clin Cancer Res, 2010; 29(1):55. doi:10.1186/1756-996629-55

Kim S, Piao J, Hwang DY, Park JS, Son Y, Hong HS. Substance $\mathrm{P}$ accelerates wound repair by promoting neovascularization and preventing inflammation in an ischemia mouse model. Life Sci, 2019; 225:98-106.

Lazarczyk M, Matyja E, Lipkowski A. Substance P and its receptors - a potential target for novel medicines in malignant brain tumour therapies (mini-review). Folia Neuropathol, 2007; 45(3):99-107.

Li J, Zeng Q, Zhang Y, Li X, Hu H, Miao X, Yang W, Zhang W, Song X, Mou L, Wang R. Neurokinin-1 receptor mediated breast cancer cell migration by increased expression of MMP-2 and MMP-14. Eur J Cell Biol, 2016; 95(10):368-77.

Mallath M, G Taylor D, Badwe R, K Rath G, Shanta V, Pramesh CS, Digumarti R, Sebastian P, Borthakur BB, Kalwar A, Kapoor S, Kumar S, Gill JL, Kuriakose MA, Malhotra H, Sharma SC, Shukla S, Viswanath L, Chacko RT, Pautu JL, Reddy KS, Sharma KS, Purushotham AD, Sullivan $R$. The growing burden of cancer in India: epidemiology and social context. Lancet Oncol, 2014; 15(6):e205-12.

Masoud V, Pagès G. Targeted therapies in breast cancer: new challenges to fight against resistance. World J Clin Oncol, 2017; 8(2):120 34; doi:10.5306/wjco.v8.i2.120

Mayordomo C, García-Recio S, Ametller E, Fernández-Nogueira P, Pastor-Arroyo EM, Vinyals L, Casas I, Gascón P, Almendro V. Targeting of substance $\mathrm{P}$ induces cancer cell death and decreases the steady state of EGFR and Her2. J Cell Physiol, 2012; 227(4):1358-66; doi:10.1002/ jcp. 22848
Mehboob R, Gilani SA, Hassan A, Tanvir I, Khan RU, Babar ME, Akram J, Ahmad F, Muñoz M, Shahi S. Prognostic significance of Substance $\mathrm{P} /$ neurokinin 1 receptor and its association with hormonal receptors in breast carcinoma. bioRxiv, 2020; doi:10.1101/2020.06.27.175083

Mehboob R, Tanvir I, Warraich RA, Perveen S, Yasmeen $\mathrm{S}$, Ahmad FJ. Role of neurotransmitter Substance P in progression of oral squamous cell carcinoma. Pathol Res Pract, 2015; 211(3):203-7; doi:10.1016/j.prp.2014.09.016

Miller KD, Nogueira L, Mariotto AB, Rowland JH, Yabroff KR, Alfano CM, Jemal A, Kramer JL, Siegel RL. Cancer treatment and survivorship statistics, 2019. CA Cancer J Clin, 2019; 69(5):363-85; doi:10.3322/caac. 21565

Mittendorf EA, Vila J, Tucker SL, Chavez-MacGregor M, Smith BD, Symmans WF, Sahin AA, Hortobagyi GN, Hunt KK. The neo-bioscore update for staging breast cancer treated with neoadjuvant chemotherapy: incorporation of prognostic biologic factors into staging after treatment JAMA Oncol, 2016; 2(7):929-36; doi:10.1001/jamaoncol.2015.6478

Muñoz M, Coveñas R. Involvement of substance $P$ and the NK-1 receptor in human pathology. Amino Acids, 2014; 46(7):1727-50; doi:10.1007/s00726-014-1736-9

Muñoz M, Crespo JC, Crespo JP, Coveñas R. Neurokinin-1 receptor antagonist aprepitant and radiotherapy, a successful combination therapy in a patient with lung cancer: a case report. Mol Clin Oncol, 2019; 11(1):50-4; doi:10.3892/mco.2019.1857

Muñoz M, González-Ortega A, Salinas-Martín MV, Carranza A, Garcia-Recio S, Almendro V, Coveñas R. The neurokinin-1 receptor antagonist aprepitant is a promising candidate for the treatment of breast cancer. Int J Oncol, 2014; 45(4):1658-72.

Muñoz M, Rosso M, Aguilar FJ, González-Moles MA, Redondo M, Esteban F. NK-1 receptor antagonists induce apoptosis and counteract substance P-related mitogenesis in human laryngeal cancer cell line HEp-2. Invest New Drugs, 2008; 26(2):111-8.

Muñoz M, Rosso M, Casinello F, Coveñas R. Paravertebral anesthesia: how substance $\mathrm{P}$ and the NK-1 receptor could be involved in regional block and breast cancer recurrence. Breast Cancer Res Treat, 2010; 122(2):601-3; doi:10.1007/s10549-010-0850-y

Munoz M, Rosso M, Covenas R. A new frontier in the treatment of cancer: NK-1 receptor antagonists. Curr Med Chem, 2010; 17(6):504-16.

Munoz M, Rosso M, Covenas R. The NK-1 receptor: a new target in cancer therapy. Curr Drug Targets, 2011; 12(6):909-21; doi: $10.2174 / 138945011795528796$

Muñoz M, Rosso M, Coveñas R, Montero I, González-Moles MA, Robles MaJ. Neurokinin-1 receptors located in human retinoblastoma cell lines: antitumor action of its antagonist, L-732,138. Invest Ophthalmol Vis Sci, 2007; 48(6):2775-81; doi:10.1167/iovs.05-1591

Muñoz M, Rosso M, Robles-Frias MJ, Salinas-Martín MV, Rosso R, González-Ortega A, Coveñas R. The NK-1 receptor is expressed in human melanoma and is involved in the antitumor action of the NK-1 receptor antagonist aprepitant on melanoma cell lines. Lab Invest, 2010; 90(8):1259-69.

Muñoz M, Rosso M. The NK-1 receptor antagonist aprepitant as a broad spectrum antitumor drug. Invest New Drugs, 2010; 28(2):187-93.

Nizam E, Erin N. Differential consequences of neurokinin receptor 1 and 2 antagonists in metastatic breast carcinoma cells; effects independent of Substance P. Biomed Pharmacoth, 2018; 108:263-70; doi:10.1016/j.biopha.2018.09.013

Olayioye MA, Neve RM, Lane HA, Hynes NE. The ErbB signaling network: receptor heterodimerization in development and cancer. Embo J, 2000; 19(13):3159-67.

Pal SK, Childs BH, Pegram M. Triple negative breast cancer: unmet medical needs. Breast Cancer Res Treat, 2011; 125(3):627-36.

Palma C. Tachykinins and their receptors in human malignancies. Curr Drug Targets, 2006; 7(8):1043-52.

Quartara L, Altamura M, Evangelista S, Maggi CA. Tachykinin receptor antagonists in clinical trials. Expert Opin Investig Drugs, 2009; 18(12):1843-64. 
Reddy BY, Greco SJ, Patel PS, Trzaska KA, Rameshwar P. RE-1-silencing transcription factor shows tumor-suppressor functions and negatively regulates the oncogenic TAC1 in breast cancer cells. Proc Natl Acad Sci, 2009; 106(11):4408; doi: 10.1073/pnas.0809130106.

Rodriguez PL, Jiang S, Fu Y, Avraham S, Avraham HK. The proinflammatory peptide substance $\mathrm{P}$ promotes blood-brain barrier breaching by breast cancer cells through changes in microvascular endothelial cell tight junctions. Int J Cancer, 2014; 134(5):1034-44.

Rosso M, Muñoz M, Berger M. The role of neurokinin-1 receptor in the microenvironment of inflammation and cancer. Sci World J, 2012; 2012:381434; doi:10.1100/2012/381434

Rugo HS. Dosing and safety implications for oncologists when administering everolimus to patients with hormone receptor-positive breast cancer. Clin Breast Cancer, 2016; 16(1):18-22.

Scharpfenecker M, Fiedler U, Reiss Y, Augustin HG. The Tie2 ligand angiopoietin-2 destabilizes quiescent endothelium through an internal autocrine loop mechanism. J Cell Sci, 2005; 118(Pt 4):771-80.

Shaik-Dasthagirisaheb YB, Varvara G, Murmura G, Saggini A, Potalivo G, Caraffa A, Antinolfi P, Tete S, Tripodi D, Conti F, Cianchetti E, Toniato E, Rosati M, Conti P, Speranza L, Pantalone A, Saggini R, Theoharides TC, Pandolfi F. Vascular endothelial growth factor (VEGF), mast cells and inflammation. Int J Immunopathol Pharmacol, 2013; 26(2):327-35; doi:10.1177/039463201302600206

Siegel RL, Miller KD, Jemal A. Cancer statistics, 2020. CA Cancer J Clin, 2020; 70(1):7-30; doi:10.3322/caac.21590

Stern DF. Tyrosine kinase signalling in breast cancer: ErbB family receptor tyrosine kinases. Breast Cancer Res, 2000; 2(3):176-83; doi:10.1186/bcr51. PubMed PMID: 11250707

Toğaçar M, Özkurt KB, Ergen B, Cömert Z. BreastNet: a novel convolutional neural network model through histopathological images for the diagnosis of breast cancer. Physica A Stat Mech Appl, 2020; 545:123592. doi:10.1016/j.physa.2019.123592

How to cite this article:

Mayuri M, Vijayakumar TM. A comprehensive review on neurokinin-1 receptor antagonism in breast cancer. J Appl Pharm Sci, 2021; 11(05):009-014. 